\title{
ANIVERSARIO Y COMPETENCIAS PROFESIONALES
}

EVENT AND PROFESSIONAL ABILITIES

Loreto Maciá Soler. Profesora Titular de Universidad. Universidad de Alicante. Departamento de Enfermería. Facultad de Ciencias de la salud.

E-mail de contacto. loreto.macia@ua.es

\section{Resumen:}

En tiempo de aniversario con 40 años de estudios de Enfermería en la Universidad en España, es importante avanzar en la mejora del cuidado de las personas.

Palabras clave: Competencias. Cuidado. Hospitalización

\section{Summary:}

In this 40th anniversary of studies of Nursing in the University in Spain, it is important to advance in the improvement of the care of people.

Keywords: Competences. Care. Hospitalization

Durante Mayo y Junio de este año 2017, es frecuente encontrar celebraciones relacionadas con los 40 años de los estudios de enfermería en el entorno universitario en España. Toda una efeméride digna de celebración, que significa una progresión profesional vinculada a cuidar mejor cada día. 
En esta tarea del cuidado, es importante incluir aspectos como profesionalidad, liderazgo o consumo de investigación y algún atributo más personal como capacidad de trabajo, empatía o paciencia, aunque estos atributos son más personales que profesionales.

Ser buenos profesionales, liderar cuidados y utilizar evidencia científica para cuidar son algunas de las competencias que se adquieren durante la formación ${ }^{(1)}$ de Enfermera responsable de cuidados generales.

Formar una buena enfermera es caro, pero si después de formar enfermeras competentes, los responsables de las instituciones sanitarias públicas o privadas, hacen que durante su vida laboral apliquen lo aprendido, seguramente se mejorara la vida de las personas, tanto en los centros de atención primaria como durante la estancia en los hospitales, domicilios y otros entornos sociales. Esta actividad, a largo plazo será más que rentable para la sociedad.

Como ejemplo podemos observar que, cuando una persona debe estar durante un tiempo ingresada en el hospital, tiene unas necesidades derivadas de la propia enfermedad y del proceso de hospitalización, unidas a la cantidad de procedimientos y técnicas a los que se somete, que van desde el lenguaje que escucha, hasta las extracciones de sangre, pasando por el entorno, comida y un largo etc de situaciones adversas que serán mejor vividas, si la enfermera responsable de sus cuidados ejerce el liderazgo de los mismos con profesionalidad.

Estos cuidados y otros que se imparten en otros escenarios diferentes requieren una especialización y conocimientos que, hace ya 40 años, las responsables de la enfermería española junto con los responsables sanitarios de la época, decidieron que debían adquirirse en la universidad, es decir en el máximo nivel académico, pero sin olvidar que Enfermería es una profesión regulada que tiene directiva comunitaria desde 1977 , modificada en $2005^{(2)}$ y en $2013^{(3)}$ donde se contempla que, los estudios de enfermería incluyen 2300 horas de prácticas clínicas realizadas en entornos clínicos y desde luego bajo la supervisión de enfermeras clínicas.

La formación teórico-práctica que representa el 50\% del plan de estudios la reciben las estudiantes de enfermería en la Universidad con profesorado que 
en su mayoría debe tener perfil enfermero con acreditación universitaria, es decir, grado académico de Doctor y experiencia docente e investigadora. En el entorno clínico, donde se cursa el 50\% del plan de estudios correspondiente a la práctica clínica, las estudiantes deben aprender siempre con las enfermeras clínicas además de asistir a sesiones de carácter científico con otros profesionales que puedan aportar complementos al cuidado, como médicos, farmacéuticos, matronas o enfermeras especialistas. En consecuencia, la formación global de los futuros enfermeros se comparte entre la Universidad y los entornos clínicos, por lo que la cohesión docencia-clínica resulta clave para una buena formación.

Desde la formación clínica es importante proyectar a las futuras enfermeras que, la responsabilidad del cuidado nunca se debe delegar en otras figuras que no sean enfermeras universitarias. Cuando se requiere ayuda para realizar cuidados, se solicita colaboración de profesionales con formación relacionada con el cuidado como el personal auxiliar de enfermería que debe hacer equipo con las enfermeras, para atender mejor a las personas, pero nunca sustituir la responsabilidad de una enfermera.

El bienestar de un paciente en el hospital empieza por preservar su dignidad y su intimidad, mantener una correcta alimentación, movilidad, higiene y comunicación. Todos estos aspectos conforman el cuidado y la responsabilidad del cuidado es de la Enfermera. Cuidar bien, implica que las personas enfermas se sientan seguras, en buenas manos y si bien, la seguridad es importante en todas las esferas de la vida, en estados de vulnerabilidad todavía es más importante.

Un servicio de tanto peso en la vida de las personas como transmitir seguridad, necesita una sólida formación que afortunadamente en España se va consolidando poco a poco, generación tras generación, donde cada grupo de enfermeras líderes van aportando su grano de arena. Hace 40 años se optó por la formación universitaria para las enfermeras y entre 1998 y 2006, se pusieron los cimientos para el desarrollo de la Enfermería científica en España ${ }^{(4)}$, por comentar aportaciones recientes que han sido clave para el desarrollo profesional. Sin embargo, si cada día las enfermeras clínicas que son las importantes de la profesión, no aplican el liderazgo del cuidado en su 
actividad diaria, el progreso real que es mejorar la vida de las personas, no terminara de llegar.

Desde la Sociedad científica SCELE felicitamos a toda la Enfermería española por su desarrollo como profesión y su aportación progresiva hacia la mejora de vida de las personas.

\section{Referencias bibliográficas.}

1. ORDEN CIN/2134/2008, de 3 de julio, por la que se establecen los requisitos para la verificación de los títulos universitarios oficiales que habiliten para el ejercicio de la profesión de Enfermero.

2. Real Decreto $1837 / 2008$, de 8 de noviembre, por el que se incorporan al ordenamiento jurídico español la Directiva 2005/36/CE, del Parlamento Europeo y del Consejo, de 7 de septiembre de 2005, y la Directiva 2006/100/CE, del Consejo, de 20 de noviembre de 2006, relativas al reconocimiento de cualificaciones profesionales, así como a determinados aspectos del ejercicio de la profesión de abogado.

3. Directiva 2013/55/UE del Parlamento Europeo y del Consejo, de 20 de noviembre de 2013, por la que se modifica la Directiva 2005/36/CE relativa al reconocimiento de cualificaciones profesionales $y$ el Reglamento (UE) no 1024/2012 relativo a la cooperación administrativa a través del Sistema de Información del Mercado Interior ("Reglamento I MI")

4. Zabalegui A. Maciá L. Desarrollo del Master oficial y Doctorado de Enfermería en España. 2010. Universitat Jaume I. Servicio de publicaciones. ISBN13: 9788480217903. 